\section{Growth Response of Major U.S. Cowpea Cultivars. I. Biomass Accumulation and Salt Tolerance}

\author{
Clyde Wilson, Xuan Liu, Scott M. Lesch, and Donald L. Suarez \\ U.S. Department of Agriculture, Agricultural Research Service, George E. Brown, \\ Jr., Salinity Laboratory, 450 West Big Springs Road, Riverside, CA 92507
}

Additional index words. cover crops, salinity, salt stress, blackeye pea, Vigna unguiculata

Abstract. Over the last several years, there has been increasing interest in amending the soil using cover crops, especially in desert agriculture. One cover crop of interest in the desert Coachella Valley of California is cowpea [Vigna unguiculata (L.) Walp.]. Cowpea is particularly useful in that as an excellent cover crop, fixing abundant amounts of nitrogen which can reduce fertilizer costs. However, soil salinity problems are of increasing concern in the Coachella Valley of California where the Colorado River water is a major source of irrigation water. Unfortunately, little information is available on the response of cowpea growth to salt stress. Thus, we investigated the growth response of 12 major cowpea cultivars ('CB5', 'CB27', 'CB46', 'IT89KD-288', 'IT93K-503-1', 'Iron Clay', 'Speckled Purple Hall', 'UCR 134', 'UCR 671', 'UCR 730', '8517', and '7964') to increasing salinity levels. The experiment was set up as a standard Split Plot design. Seven salinity levels ranging from 2.6 to $20.1 \mathrm{dS} \cdot \mathrm{m}^{-1}$ were constructed, based on Colorado River water salt composition, to have $\mathrm{NaCl}, \mathrm{CaCl} 2$ and $\mathrm{MgSO} 4$ as the salinization salts. The osmotic potential ranged from -0.075 to $-0.82 \mathrm{MPa}$. Salt stress began 7 days after planting by adding the salts into irrigating nutrient solution and ended after 5 consecutive days. The plants were harvested during flowering period for biomass measurement (53 days after planting). Data analysis using SAS analysis of variance indicated that the salinity in the range between 2.6 and 20.1 $\mathrm{dS} \cdot \mathrm{m}^{-1}$ significantly reduced leaf area, leaf dry weight, stem dry weight and root dry weight $(P \leq 0.05)$. We applied the data to a salt-tolerance model, $\log (Y)=a_{1}+a_{2} X+a_{3} X^{2}$, where $Y$ represents biomass, $a_{1}, a_{2}$ and $a_{3}$ are empirical constants, and $X$ represents salinity, and found that the model accounted for $99 \%, 97 \%, 96 \%, 99 \%$, and $96 \%$ of salt effect for cowpea shoot, leaf area, leaf dry weight, stem dry weight and root dry weight, respectively. We also found significant differences $(P \leq 0.05)$ of each biomass parameter among the 12 cultivars and obtained different sets of the empirical constants to quantitatively describe the response of each biomass parameter to salinity for individual cowpea cultivars. Since a significant salt $\times$ cultivar interaction effect $(P \leq 0.05)$ was found on leaf area and leaf dry weight, we concluded that salt tolerance differences exist among the tested cultivars.

Over the last several years, there has been increasing interest in amending the soil using cover crops, manures, composted yard wastes, and other organic matter. Covers crops are important in maintaining soil productivity and environmental quality (Hargrove and Fry, 1987; Powers, 1987). More recently, this interest has expanded to include desert agriculture (Guldan et al., 1997; Hutchinson and McGiffen, 2000).

The desert valleys of southern California have become a proficient producer of a large variety of vegetables (Mayberry et al., 1995). Although hot and arid, these low-desert val-

Received for publication 2 Dec. 2002. Accepted for publication 27 Sept. 2005. Seeds were provided by the Cowpea Research and Breeding group of Department of Botany and Plant Sciences, University of California, Riverside. We thank Dr. Jeffrey D. Ehlers for his assistance throughout this project. Mention of company names or products is for the benefit of the reader and does not imply endorsement, guarantee, or preferential treatment by the USDA or its agents.

${ }^{1}$ To whom reprint requests should be addressed; e-mail cwilson@ussl.ars.usda.gov. leys are well suited to growing high-value fruit and winter vegetables as well as other crops if properly irrigated. However, as pointed out by Hutchinson and McGiffen (2000), any cropping system employing the use of cover crops would need to fit into the vegetable production timetable of desert agriculture. Because October. DLS refers to delayed leaf senescence cultivars. cowpea (Vigna unguiculata) is adapted to high temperature and drought (Ehlers and Hall, 1997; Hall and Patel, 1985), it has become one cover crop of some interest as it may be suitable for growth during summer months in the desert valleys of California when vegetables are not usually grown. Recently, Abdul-Baki, et al. (1998) suggested an approach whereby cowpea could be used as a second cover crop in date orchards by seeding them in late May after terminating Lana vetch. Recently, Hutchinson and McGiffen (2000) indicated that cowpea may also be useful as a mulch for weed control in the low desert.

In desert agriculture though, salinity is a widespread and prevalent problem. Soil salinity in the Coachella Valley of California ranges from 1 to $150 \mathrm{dS} \cdot \mathrm{m}^{-1}$ (S. Aslan, personal communication) and salinity problem is of increasing concern there where the Colorado River water has been a major source of irrigation water $\left(\right.$ salinity $=1.1$ to $1.2 \mathrm{dS} \cdot \mathrm{m}^{-1}$ ) for many years (Bower et al., 1969). Additionally, high-quality water for agricultural purposes is becoming increasingly scare due to changing environmental standards and rising demands from urban areas. The future of irrigated agriculture, in the desert and elsewhere, will need to include the use of waters containing higher levels of soluble salts.

Unfortunately, little information is available on the response of cowpea growth to increasing salinity. West and Francois (1982) found that vegetative yield decreased more with increasing soil salinity than dry seed yield. Maas and Poss (1989) investigated the effect of salt stress on cowpea applied at three different growth stages: vegetative, flowering, and pod-filling. They found that pod and seed yields were most sensitive to salinity during the vegetative stage. Vegetative growth was reduced by salinity during all three growth stages studied but the effect was much less when the stress was imposed during the last two stages. However, these prior investigations were concerned exclusively with 'CB5', 'California Blackeye No. 5'. Other cultivars such as 'Iron Clay' may be better suited for the Coachella Valley (Abdul-Baki, 1998). Therefore, any information regarding salt

Table 1. Cowpea cultivars used in the experiment. Cultivars 1 to 7 (counted from the top), are popular Coachella Valley cover crops with different origins and growth traits. Cultivar 9, 'CB27', is a new variety which demonstrates high heat tolerance and broad-based resistance to both Fusarium wilt and root-knot nematodes. Cultivar 10, 'CB46', is a new, widely planted cultivar and now accounts for $80 \%$ to $90 \%$ of the area planted in the U.S. Cultivar 8 , 'CB5', is an old standard cultivar which now accounts for only $5 \%$ to $10 \%$ of the area planted. The flowering term normal refers to cultivars that flower in normal growth period. Late or photosensitive refers to cultivars that do not flower until September or

\begin{tabular}{lll}
\hline Cultivar & Flowering time & Origin \\
\hline Iron Clay (standard variety) & Late & Southeastern U.S. \\
Speckled Purple Hall & Late & Southeastern U.S. \\
IT89KD-288 & Photosensitive & Nigeria \\
IT93K-503-1 & Photosensitive & Nigeria \\
UCR 134 & Photosensitive & Botswana \\
UCR 671 & Photosensitive & Botswana \\
UCR 730 & Photosensitive & Kenya \\
CB5 (California Blackeye) & Normal & California \\
CB27 (new variety) & Normal & California \\
CB46 (standard variety) & Normal & California \\
7964 (DLS) & Normal & Southeastern U.S. \\
8517 (DLS) & Normal & California \\
\hline
\end{tabular}


Table 2. Salt levels and composition for irrigation solution added to simulate increasing Colorado River water salt compositions. Solutions were prepared using City of Riverside municipal water with an $\mathrm{EC}$ value around $0.55 \mathrm{dS} \cdot \mathrm{m}^{-1}$ and having about (in $\mathrm{meq} \cdot \mathrm{L}^{-1}$ ): $3.3 \mathrm{Ca}, 1.6 \mathrm{Na}, 0.1 \mathrm{~K}, 0.83 \mathrm{Cl}, 1.36 \mathrm{NO}$, and 1.44 $\mathrm{SO}_{4}$, which were included in the salt composition.

\begin{tabular}{|c|c|c|c|c|c|c|c|}
\hline \multirow{2}{*}{$\begin{array}{l}\text { Salinity } \\
\text { level } \\
\left(\mathrm{dS} \cdot \mathrm{m}^{-1}\right)\end{array}$} & \multirow{2}{*}{$\begin{array}{c}\text { Osmotic } \\
\text { potential } \\
(\mathrm{MPa})\end{array}$} & \multicolumn{6}{|c|}{ Salt composition $\left(\mathrm{meq} \cdot \mathrm{L}^{-1}\right)$} \\
\hline & & $\mathrm{Ca}$ & $\mathrm{Mg}$ & $\mathrm{Na}$ & $\mathrm{K}$ & $\mathrm{SO}_{4}$ & $\mathrm{Cl}$ \\
\hline 2.6 & -0.08 & 8.3 & 3.0 & 1.6 & 6.1 & 4.4 & 2.8 \\
\hline 3.7 & -0.15 & 8.3 & 6.0 & 12.1 & 6.1 & 7.4 & 13.3 \\
\hline 5.4 & -0.19 & 11.1 & 12.1 & 22.5 & 6.1 & 13.5 & 26.5 \\
\hline 8.3 & -0.31 & 18.4 & 25.3 & 45.2 & 6.1 & 26.7 & 54.5 \\
\hline 12.1 & -0.47 & 26.0 & 38.8 & 68.5 & 6.1 & 40.2 & 87.4 \\
\hline 17.3 & -0.69 & 38.5 & 62.3 & 108.6 & 6.1 & 63.7 & 140.0 \\
\hline 20.1 & -0.82 & 44.0 & 77.8 & 135.6 & 6.1 & 79.2 & 172.7 \\
\hline
\end{tabular}

tolerance among cowpea cultivars could be useful in addressing the current issues involved in desert agriculture.

There is mixed evidence in the literature as to whether salt tolerance can vary among cultivars within a given crop. For example, Francois (1996) investigated four sunflower hybrids and found similar threshold values for seed yield $\left(4.8 \mathrm{dS} \cdot \mathrm{m}^{-1}\right)$. Conversely, among bermudagrass cultivars, Francois (1988) reported widely ranging threshold values of 2.7, 8.4, and 10.3 $\mathrm{dS} \cdot \mathrm{m}^{-1}$ for the cultivars 'Tifton 10 ', 'Tifway II', and 'Tifton 86', respectively.

Just as important, it seems that salt tolerance among cultivars may vary with one component of yield but not another. Francois et al. (1988) showed that two cultivars of triticale, 'Cananea' and 'Beaguelita', had similar threshold values for relative grain yield but differed with respect to relative straw yield. Finally, Leng et al. (2001) identified wide genotypic differences in relative salt tolerance within rice and found that their relative salt tolerance ranking varied depending on the parameter measured.

Thus, we examined the hypothesis that there exists wide salt tolerance in the vegetative growth among cowpea cultivars. We investigated the growth response of 12 major cowpea cultivars, which may be useful as cover crops in desert agriculture, to increasing salinity levels using sand cultures: 'UCR 730', 'IT89KD288', 'Iron Clay', 'IT93K-503-1', 'Speckled Purple Hall', 'UCR 134', 'UCR 671', 'CB5', 'CB27', '8517', '7964', and 'CB46'. We also used the salt tolerance model of van Genuchten and Hoffman (1984) to ascertain the salinity level resulting in a $50 \%$ decrease $\left(\mathrm{C}_{50}\right.$ value $)$ in the growth parameter studied.

\section{Materials and Methods}

Experimental design. The cowpea experiment was set up as a standard split plot design, with salt as the main plot variable, and cowpea cultivar as the subplot variable. The experiment consisted of 12 cultivars of cowpea (Table 1) subjected to seven different levels of salinity (Table 2). The entire experimental design was replicated across three plots $(1$ plot $=1$ sand tank, 21 sand tanks used in total). In all, there were $252(12 \times 7 \times 3)$ observations for each yield response variable. Seeds were obtained from the Cowpea Research and Breeding Group, Department of Botany and Plant Sciences, University of California, Riverside.

Planting. The 12 cultivars were planted in greenhouses in two rows in each sand tank based on a random cultivar map generated by SAS PLAN procedure. The greenhouses were located at Riverside, California (lat. 33०58'24"N, long. $\left.117^{\circ} 19^{\prime} 12^{\prime \prime} \mathrm{W}\right)$. The tanks measured 1.2 $\times 0.6 \times 0.5 \mathrm{~m}$ deep and contained washed sand having an average bulk density of $1.2 \mathrm{Mg} \cdot \mathrm{m}^{-3}$. At saturation, the sand has an average volumetric water content of $0.34 \mathrm{~m}^{3} \cdot \mathrm{m}^{-3}$. The plant were spaced $17 \times 20 \mathrm{~cm}$ apart. Two seeds were sown a half-inch deep at each space on 18 July 2000. After gemination, the plants were thinned to one at each space.

Growth conditions. The temperature, radiation, and humidity were automatically recorded hourly at a point slightly above the plant canopy. Over the course of the investigation the air temperature ranged 32 to $35^{\circ} \mathrm{C}$ day and 15 to $18{ }^{\circ} \mathrm{C}$ night. Relative humidity ranged from $43 \%$ to $52 \%$. Plants were irrigated three times daily with a base nutrient solution made up with City of Riverside municipal water. The composition of base nutrient solution(BNS) for irrigation was a modified (about $80 \%$ strength) Hoagland solution consisting of (in $\mathrm{mol} \cdot \mathrm{m}^{-3}$ ): $2.5 \mathrm{Ca}\left(\mathrm{NO}_{3}\right)_{2}, 4.0 \mathrm{KNO}_{3}, 2.0 \mathrm{KCl}, 3.0 \mathrm{NH}_{4} \mathrm{NO}_{3}$, $0.36 \mathrm{KH}_{2} \mathrm{PO}_{4}, 1.5 \mathrm{MgSO}_{4}, 0.10 \mathrm{Fe}$ as sodium ferric diethylenetriamine pentaacetate, 0.023 $\mathrm{H}_{3} \mathrm{BO}_{3}, 0.015 \mathrm{MnSO}_{4}, 0.0012 \mathrm{ZnSO}_{4}, 0.0003$ $\mathrm{CuSO}_{4}$, and $0.0001 \mathrm{H}_{3} \mathrm{MoO}_{4}$. The BNS served as the control treatment. Each irrigation was of 5 min duration (three times daily) which allowed the sand to become completely saturated, after which the solution drained into 765-Lreservoirs for reuse in the next irrigation cycle. Water lost by evapotranspiration was replenished automatically each day with deionized water to maintain constant electrical conductivities in the solutions. The $\mathrm{pH}$ was adjusted weekly using concentrated $\mathrm{H}_{2} \mathrm{SO}_{4}$ and maintained between 6.5 and 7.5.

Salt treatment. Salinization commenced $7 \mathrm{~d}$ after planting and continued for up to 6 consecutive days until the highest salt level was achieved. Equivalent amounts of salts were added incrementally each day to avoid osmotic shock to the seedlings. These irrigation waters were prepared to simulate the increasingly saline waters derived from Colorado River water using $\mathrm{NaCl}, \mathrm{CaCl}_{2}$, and $\mathrm{MgSO}_{4}$. Final ion compositions are shown in Table 2. The final electrical conductivities of the irrigation waters $\left(\mathrm{EC}_{\mathrm{i}}\right)$ were 2.6 (control, the lowest salinity we obtained using tap water for the preparation of the irrigating solution), 3.7, 5.4, 8.3, 12.1, 17.3, and $20.1 \mathrm{dS} \cdot \mathrm{m}^{-1}$.

Biomass determination. Plants were harvested on 9 Sept. 2000, $53 \mathrm{~d}$ after planting when the cultivars with a normal flowering period passed flower initiation stage. The harvested plants were immediately brought to the laboratory for processing. Root zone up to stem base was washed with tap and then deionized water to remove surface ions. The root surface was dried using paper. The washed plants were separated into leaf blades, stems including petioles, and roots, then placed into paper bags and oven-dried at $45^{\circ} \mathrm{C}$ for $7 \mathrm{~d}$.

Before drying, the fresh leaf-blade area was measured using LI-COR 3100 area meter. The dried biomass was weighed using Sartorius Universal balance (accuracy $=0.01 \mathrm{~g}$ ) for larger samples and MettlerAC 100 (accuracy $=0.0001$ g) balances for smaller samples.

\section{Data analysis}

Salt-tolerance model. The data for each cultivar was analyzed using a salt-tolerance model proposed by van Genuchten and Hoffman (1984),

$\mathrm{y}=\delta \exp \left(\alpha \mathrm{x}-\beta \mathrm{x}^{2}\right)$

where $\mathrm{y}$ is biomass yield, $\mathrm{x}$ is salinity, and $\delta$, $\alpha$, and $\beta$ are empirical parameters. Equation [1] describes the relationship between yield and salinity as a smooth, continuous equation. It can be converted into an ordinary regression equation using a $\log$ transformation, which facilitates stabilizing biomass variance.

The standard split-plot analysis of variance (ANOVA) model Under a log transformation, Eq. [1] becomes

$\log (\mathrm{y})=\log (\delta)+\alpha \mathrm{x}-\beta \mathrm{x}^{2}+\xi=\beta_{0}+\beta_{1} \mathrm{x}+\beta_{2} \mathrm{x}^{2}$ $+\xi$

which is a simple quadratic regression equation. In Eq. [2], $\xi$ represents the residual error component, which is assumed to be independent and follow the standard normality. Additionally, $\beta_{2}$ is assumed to be $\leq 0$. When multiple cultivars are being analyzed, Eq. [2] could be expanded into one of the two more general linear models shown below:

$\log \left(y_{j}\right)=\beta_{0 j}+\beta_{1 j} x+\beta_{2 j} x^{2}+\xi$

$\log \left(y_{j}\right)=\beta_{0 j}+\beta_{1} x+\beta_{2} x^{2}+\xi$

where $y_{j}$ is the yield for the $j^{\text {th }}$ cultivar. These three models can be categorized as follows:

\begin{tabular}{|c|c|c|}
\hline Eq. & $\begin{array}{l}\text { Model } \\
\text { type }\end{array}$ & Interpretation \\
\hline [3] & Full interaction & $\begin{array}{l}\text { Unique salt-tolerance } \\
\text { curves }\end{array}$ \\
\hline [4] & No interaction & $\begin{array}{l}\text { Constant salt-tolerance } \\
\text { curves having unique } \\
\text { intercepts }\end{array}$ \\
\hline$[2]$ & No interaction & $\begin{array}{l}\text { Identical salt-tolerance } \\
\text { curves (no cultivar } \\
\text { differences) }\end{array}$ \\
\hline
\end{tabular}




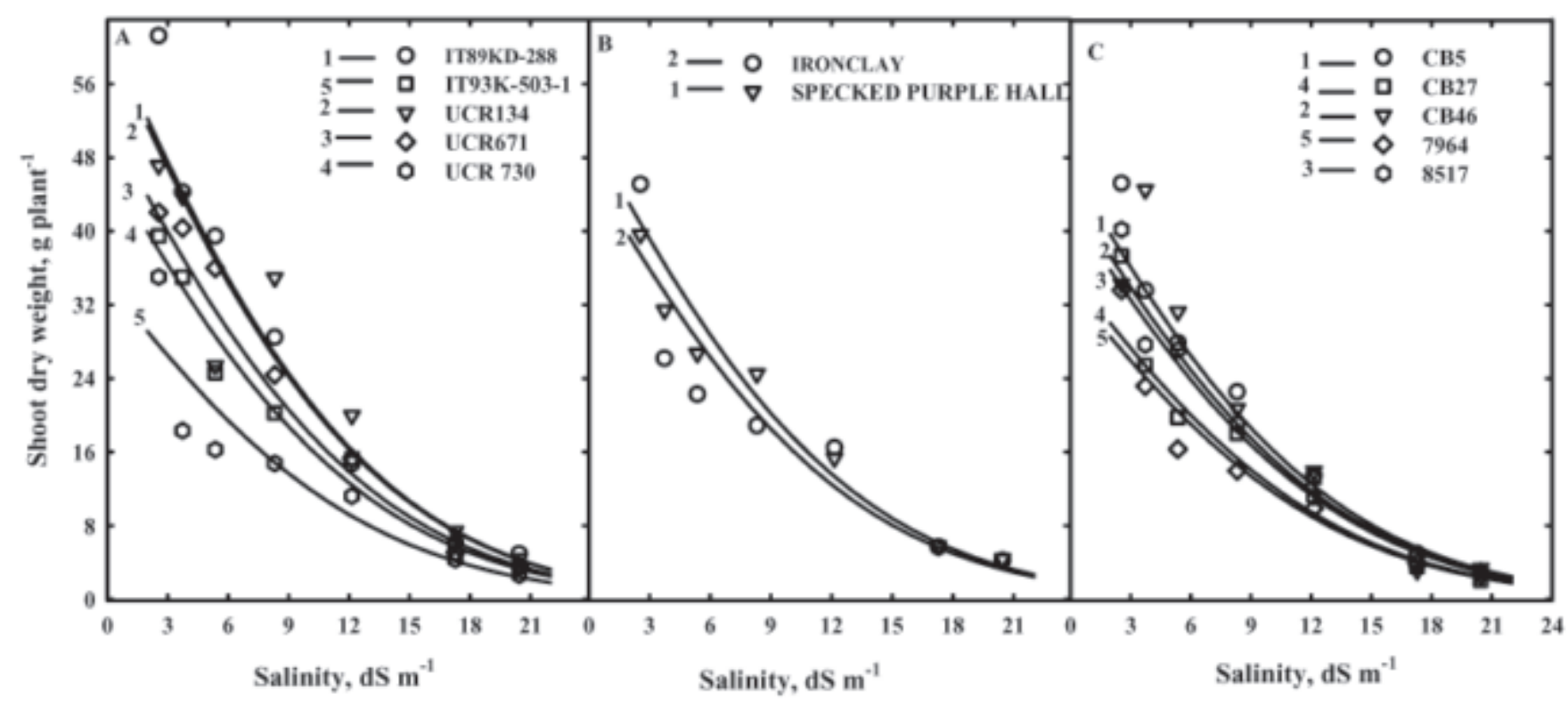

Fig. 1. Observed data (symbol) (average of block) and predicted curves of shoot (leaf + stem) dry weight salt tolerance (averaged across blocks) of cowpea cultivars with different flowering times: (A) photosensitive, (B) late, and (C) normal. Numbers are yield order.

Table 3. Model-predicted maximum shoot (leaf + stem) dry weight (dwt) (Ymax) and salinity levels that could result in a $50 \%$ reduction of Ymax $\left(\mathrm{C}_{50}\right)$ for the 12 cowpea cultivars tested. All model-predicted $Y$ max values occurred at 0.0 $\mathrm{dS} \cdot \mathrm{m}^{-1}$. Values are sorted by the Ymax.

\begin{tabular}{lcc}
\hline \multirow{2}{*}{ Cultivar } & \multicolumn{2}{c}{ Shoot dry wt } \\
\cline { 2 - 3 } $\mathrm{C}_{50}\left(\mathrm{dS} \cdot \mathrm{m}^{-1}\right)$ & Ymax $(\mathrm{g} /$ plant $)$ \\
\hline IT89KD-288 & 7.0 & 62.1 \\
UCR 134 & 7.0 & 61.2 \\
UCR 671 & 7.0 & 52.1 \\
Speckled Purple Hall & 7.0 & 51.2 \\
IT93K-503-1 & 7.0 & 47.5 \\
CB5 & 7.0 & 47.2 \\
Iron Clay & 7.0 & 46.9 \\
CB46 & 7.0 & 44.3 \\
8517 & 7.0 & 42.5 \\
CB27 & 7.0 & 35.7 \\
UCR 730 & 7.0 & 34.6 \\
7964 & 7.0 & 33.9 \\
\hline
\end{tabular}

The above various salt-tolerance models can be directly analyzed using the split-plot ANOVA model in SAS GLM procedure (SAS Institute, 1994).

\section{Results}

Shoot dry weight. A nonlinear reduction of shoot (leaf dry weight + stem dry weight) dry-matter accumulation with increasing levels of salinity was found for all the 12 cowpea cultivars examined $(P<0.0001)$ (Fig. 1A-C). The salt-tolerance model of equation (1) best described the response of shoot dry-weight data to increasing salt levels and accounted for $99 \%$ of total salt effect. The six highest shoot-yielding cultivars were 'IT89KD-288', 'UCR134', 'UCR 671', 'Speckled Purple Hall', 'IT93-503-1', and 'CB5' (Table 3). 'IT89KD288 ' appeared the highest yielding cultivar.

No significant salinity $\times$ cultivar interaction effects $(P>0.05)$ was found for shoot dry weight. Therefore, equation (4), having unique intercepts $\left(\beta_{0 j}, j=1,2, \ldots 12\right)$, was used to generate the predicted curves in Fig. $1 \mathrm{~A}-\mathrm{C}$. According to model-estimated maximum yield values, the salinity level resulting in a $50 \%$ shoot biomass reduction $\left(\mathrm{C}_{50}\right)$ was the same for the 12 cultivars, $7.0 \mathrm{dS} \cdot \mathrm{m}^{-1}$ (Table 3 ).

Leaf area and dry weight. A nonlinear reduction of leafarea and dry matter accumulation with increasing levels of salinity was also found for all the 12 tested cowpea cultivars $(P$ $<0.0001$ ) (Figs. 2A-C and 3A-C). The salttolerance model of Eq. [1] adequately described the response of leaf area and dry weight data to increasing salt levels and accounted for $97 \%$ and $96 \%$ of the total salt effect, respectively. Additionally, it was observed that the cowpea leaf number decreased with increasing salinity levels (data not shown). Furthermore, much smaller trifoliate was observed at higher salt stress levels on each tested cultivar. Collectively, these observations indicate that salt stress reduced leaf growth and biomass accumulation by affecting leaf differentiation and expansion.

As a group, the cover crop cultivars 'Iron Clay', 'IT89KD-288', 'IT93-503-1', 'Speckled PurpleHall', 'UCR 134', 'UCR 671', and 'UCR 730 ', appeared to have greater model-predicted yield maximums (Ymax) for leaf area and leaf dry weight than those cultivars with normal flowering time ('CB5', 'CB27', 'CB46', '7964', and ' 8517 '), although this was not necessarily true for all cases (Tables 4 and 5). The six highest yielding cultivars in terms of leaf area were 'IT89KD-288', 'UCR 671', 'UCR 134', 'Iron Clay', 'Speckled Purple Hall', and '8517'(Table 4). All model-predicted Ymax values occurred at $0.0 \mathrm{dS} \cdot \mathrm{m}^{-1}$. With respect to leaf dry weight, the 6 highest yielding cultivars were 'IT89KD288', 'CB46', 'UCR 671', '8517', 'CB5', and 'UCR 134'(Table 5). All model-predicted Ymax values occurred at $0.0 \mathrm{dS} \cdot \mathrm{m}^{-1}$ except for ' $\mathrm{UCR}$ $134^{\prime}$, which occurred at $0.37 \mathrm{dS} \cdot \mathrm{m}^{-1}$.

With respect to all parameters examined, leaf area, leaf dry weight, stem dry weight, and root dry weight, 'IT89KD-288' was the highest yielding under control conditions (Figs. 1-5). However, based on the $\mathrm{C}_{50}$ values, the salinity level resulting in a $50 \%$ reduction of maximum yield, for leaf area and dry weight, it was among the most sensitive cultivars.

A significant salinity $\times$ cultivar interaction effects $(P \leq 0.05)$ was also detected for leaf area and leaf dry weight using the split-plot ANOVA model analysis indicating that salttolerance differences exist among the tested cultivars. Therefore, the full interaction salttolerance model of Eq. [3] was used and the corresponding intercept $\left(\beta_{0 \mathrm{j}}\right)$, linear term $\left(\beta_{\mathrm{lj}}\right)$ and quadratic term $\left(\beta_{2 j}\right)(j=1,2, \ldots 12)$ for 12 cultivars were estimated to generate the predicted curves in Figs. $2 \mathrm{~A}-\mathrm{C}$ and $3 \mathrm{~A}-\mathrm{C}$. Among the 12 cultivars investigated, the $\mathrm{C}_{50}$ varied from 3.4 to $8.3 \mathrm{dS} \cdot \mathrm{m}^{-1}$ and from 5.6 to $12.1 \mathrm{dS} \cdot \mathrm{m}^{-1}$ for leaf area and dry weight, respectively (Tables 4 and 5). Salt tolerance was thus ranked based on leaf area $\mathrm{C}_{50}$ values calculated for the 12 cultivars (Table 4). Using this measure, 'UCR 134' demonstrated the highest salt tolerance.

Stem dry weight. A nonlinear reduction of stem dry-matter accumulation with increasing levels of salinity was also found for all the 12 cowpea cultivars examined $(P<0.0001)$ (Fig. 4A-C). Again, the salt-tolerance model of equation (1) best described the response of stem dry-weight data to increasing salt levels and accounted for $99 \%$ of total salt effect. Salt stress appeared to limit stem-yield production by limiting stem growth in length and branching as shorter stems and fewer branches were observed with increasing salinity levels (data not shown).

The six highest stem-yielding cultivars were 'IT89KD-288', 'UCR134', 'UCR 671', 'IT93503-1', 'CB5', and 'Speckled Purple Hall' (Table 6). IT89KD-288 was again the highest yielding cultivar and appeared to be statistically different from the other high-yielding 


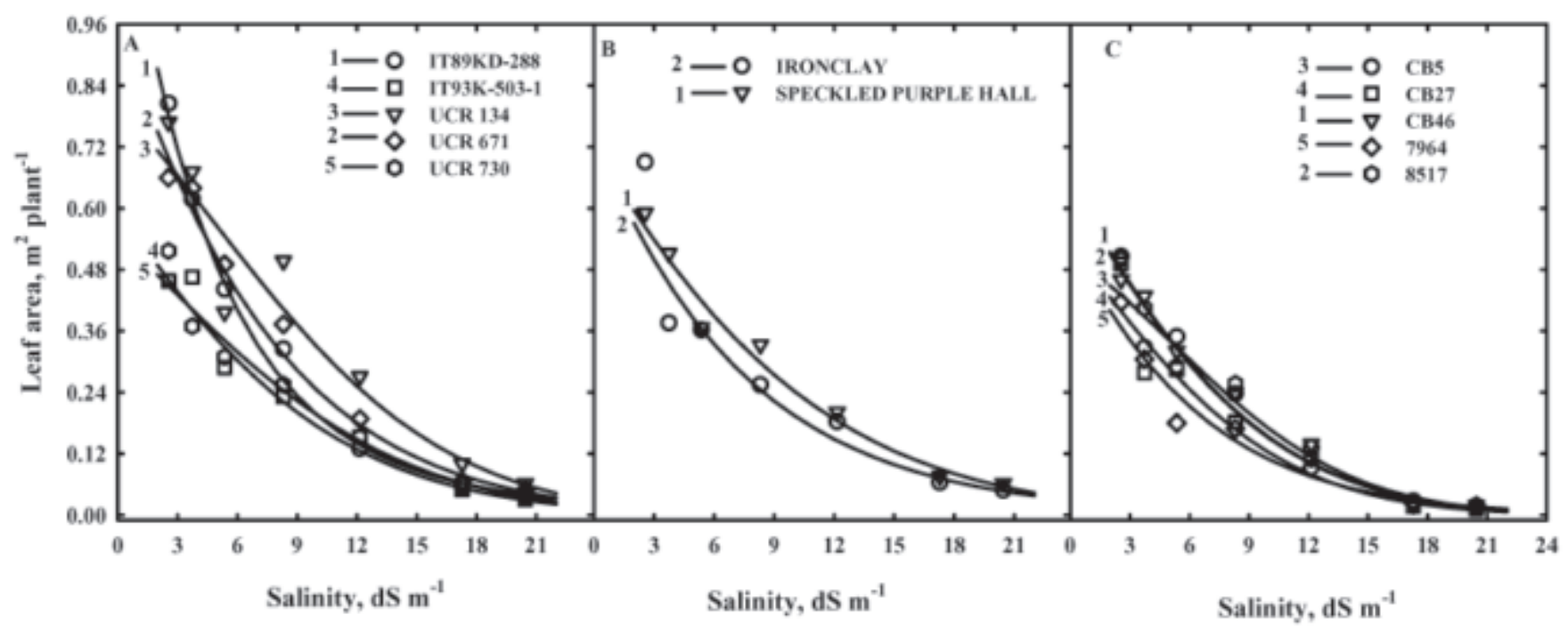

Fig. 2. Observed data (symbol) (average of block) and predicted curves (lines) of leaf area salt tolerance (averaged across blocks) of cowpea cultivars with different flowering times: (A) photosensitive, (B) late, and (C) normal. Numbers are yield order.

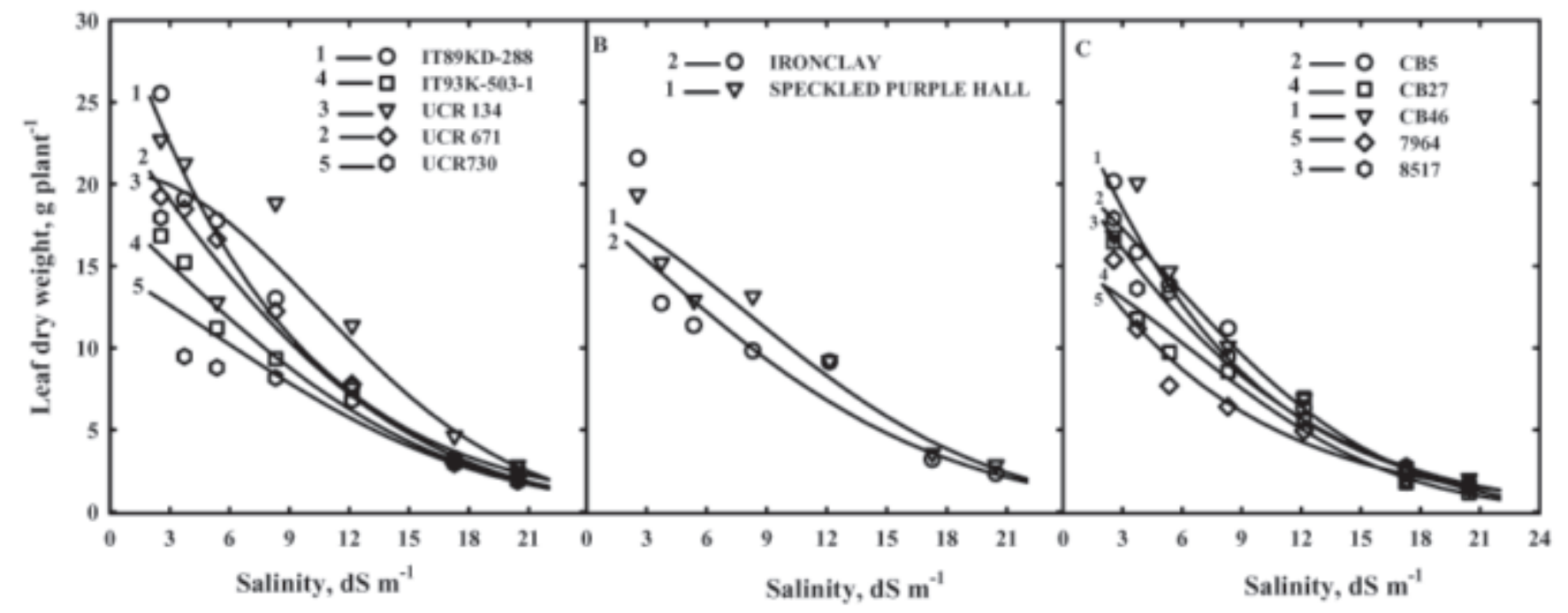

Fig. 3. Observed data (symbol) (average of block) and predicted curves of leaf dry weight salt tolerance (averaged across blocks) of cowpea cultivars with different flowering times: (A) photosensitive, (B) late, and (C) normal. Numbers are yield order.

cultivars based on the results of the individual mean difference significance $t$ tests.

No significant salinity $\times$ cultivar interaction effects $(P>0.05)$ was found for stem dry-weight. Therefore, equation (4), having unique intercepts $\left(\beta_{0 ;}, \mathrm{j}=1,2, \ldots 12\right)$, was used to generate the predicted curves in Fig. 4 A-C. According to model-estimated maximum yield values, the salinity level resulting in a $50 \%$ stem biomass reduction $\left(\mathrm{C}_{50}\right)$ was the same for the 12 cultivars, $6.2 \mathrm{dS} \cdot \mathrm{m}^{-1}$ (Table 6 ).

Root dry weight. As with stem dry weight, a nonlinear reduction of root dry-matter accumulation with increasing levels of salinity was also found for all the 12 tested cowpea cultivars $(P<0.0001)$ (Fig. 5A-C). The salt-tolerance model of Eq. [1] best described the response of root dry weight data to salt levels and accounted for $96 \%$ of total salt effect. The 6 highest root-yielding cultivars were 'IT89KD-288', 'IT93-503-1', 'UCR134', 'CB5', 'CB46', and 'Speckled Purple Hall' (Table 6). All modelpredicted Ymax values occurred at $1.1 \mathrm{dS} \cdot \mathrm{m}^{-1}$.
'IT89KD-288' was again the highest yielding and appeared to be statistically different from the other high-yielding cultivars based on

Table 4. Model-predicted maximum leaf area (Ymax) and salinity levels that could result in a $50 \%$ reduction of $Y \max \left(\mathrm{C}_{50}\right)$ for the 12 cowpea cultivars tested. All model-predicted Ymax values occurred at $0.0 \mathrm{dS} \cdot \mathrm{m}^{-1}$. Values are sorted by the $\mathrm{C}_{50}$.

\begin{tabular}{lcc}
\hline & \multicolumn{2}{c}{ Leaf area } \\
\cline { 2 - 3 } Cultivar & $\mathrm{C}_{50}\left(\mathrm{dS} \cdot \mathrm{m}^{-1}\right)$ & Ymax $\left(\mathrm{m}^{2} /\right.$ plant $)$ \\
\hline UCR 134 & 8.3 & 0.80 \\
CB5 & 7.4 & 0.51 \\
UCR 730 & 7.3 & 0.55 \\
Speckled Purple Hall & 6.7 & 0.72 \\
IT93K-503-1 & 6.0 & 0.60 \\
CB27 & 5.5 & 0.53 \\
CB46 & 5.4 & 0.64 \\
8517 & 5.4 & 0.65 \\
UCR 671 & 5.2 & 0.97 \\
Iron Clay & 5.2 & 0.74 \\
7964 & 4.5 & 0.54 \\
IT89KD-288 & 3.4 & 1.32
\end{tabular}

the results of the individual mean difference significance $t$ tests.

Table 5. Model-predicted maximum leaf dry weight (dwt) (Ymax) and salinity levels that could result in a $50 \%$ reduction of $Y \max \left(\mathrm{C}_{50}\right)$ for the 12 cowpea cultivars tested. All model-predicted Ymax values occurred at $0.0 \mathrm{dS} \cdot \mathrm{m}^{-1}$, except for UCR134 which occurred at $0.37 \mathrm{dS} \cdot \mathrm{m}^{-1}$. Values are sorted by the $\mathrm{C}_{50}$.

\begin{tabular}{lcc}
\hline & \multicolumn{2}{c}{ Leaf dry wt } \\
\cline { 2 - 3 } Cultivar & $\mathrm{C}_{50}\left(\mathrm{dS} \cdot \mathrm{m}^{-1}\right)$ & Ymax $(\mathrm{g} /$ plant $)$ \\
\hline UCR 134 & 12.1 & 20.6 \\
Speckled Purple Hall & 10.8 & 18.9 \\
UCR 730 & 9.6 & 14.8 \\
Iron Clay & 9.0 & 18.6 \\
CB27 & 8.9 & 15.2 \\
IT93K-503-1 & 8.5 & 18.5 \\
CB5 & 8.4 & 20.7 \\
UCR 671 & 7.7 & 24.2 \\
8517 & 6.8 & 21.4 \\
7964 & 6.0 & 17.5 \\
IT89KD-288 & 5.8 & 32.0 \\
CB46 & 5.6 & 26.6
\end{tabular}




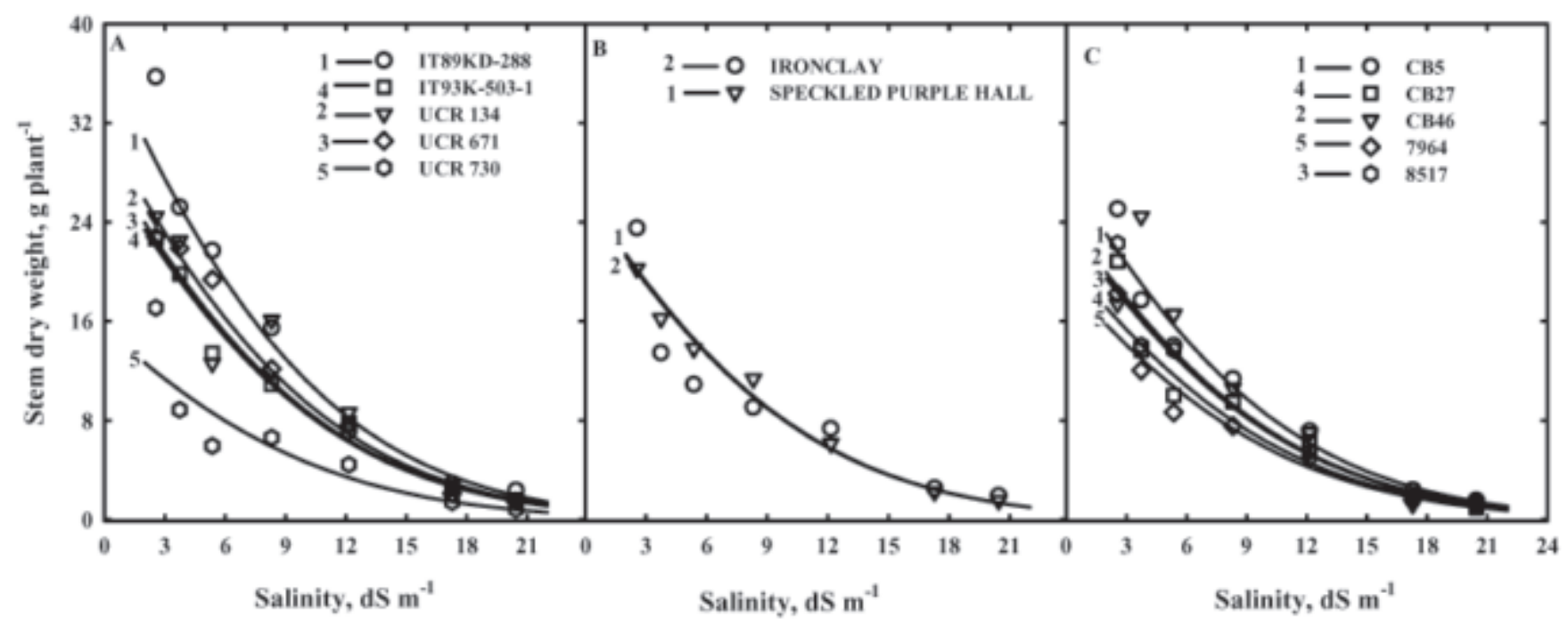

Fig. 4. Observed data (symbol) (average of block) and predicted curves of stem dry weight salt tolerance (averaged across blocks) of cowpea cultivars with different flowering times: (A) photosensitive, (B) late, and (C) normal. Numbers are yield order.

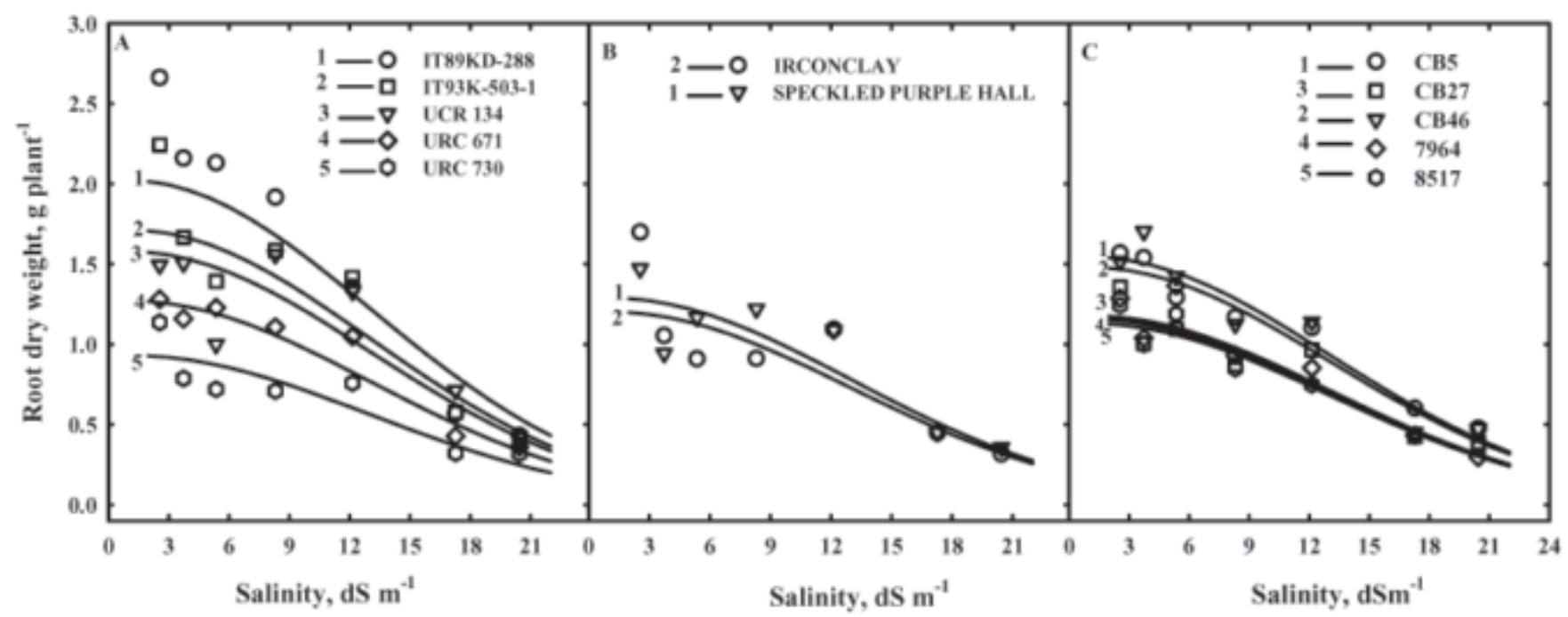

Fig. 5. Observed data (symbol) (average of block) and predicted curves of root dry weight salt tolerance (averaged across blocks) of cowpea cultivars with different flowering times: (A) photosensitive, (B) late, and (C) normal. Numbers are yield order.

No significant salinity $\times$ cultivar interaction effects $(P>0.05)$ were found for root dry weight. Therefore, Eq. [4] $\left(\beta_{0 j}, \mathrm{j}=1,2, \ldots 12\right)$ was again used to generate predicted curves in Fig. 5A-C. According to model-estimated maximum yield values, the salinity level resulting in a $50 \%$ root biomass reduction $\left(\mathrm{C}_{50}\right)$ was the same for the 12 cultivars, $15.2 \mathrm{dS} \cdot \mathrm{m}^{-1}$ (Table 6). In cowpea, it appears that while roots have less total biomass they appear to be less affected by salinity stress than stems and leaves.

\section{Discussion}

Salt tolerance was investigated among cowpea cultivars grown using irrigation waters of a mixed-salt salinity based on Colorado River waters. The results from our sand tank experiments demonstrate that significant differences in salt tolerance exist among cowpea cultivars with respect to leaf area and leaf dry weight. All cultivars exhibited a nonlinear reduction

Table 6. Model-predicted maximum stem and root dry weight (dwt) (Ymax) and salinity levels that could result in a $50 \%$ reduction of $Y \max \left(\mathrm{C}_{50}\right)$ for the 12 cowpea cultivars tested. All model-predicted Ymax values occurred at $0.0 \mathrm{dS} \cdot \mathrm{m}^{-1}$, for stems and $1.1 \mathrm{dS} \cdot \mathrm{m}^{-1}$ for roots.

\begin{tabular}{|c|c|c|c|c|}
\hline \multirow[b]{2}{*}{ Cultivar } & \multicolumn{2}{|c|}{ Stem dry wt } & \multicolumn{2}{|c|}{ Root dry wt } \\
\hline & $\overline{\mathrm{C}_{50}\left(\mathrm{dS} \cdot \mathrm{m}^{-1}\right)}$ & Ymax (g/plant) & $\mathrm{C}_{50}\left(\mathrm{dS} \cdot \mathrm{m}^{-1}\right)$ & Ymax (g/plant) \\
\hline UCR 134 & 6.2 & 31.6 & 15.2 & 1.58 \\
\hline Speckled Purple Hall & 6.2 & 26.3 & 15.2 & 1.29 \\
\hline UCR 730 & 6.2 & 15.5 & 15.2 & 0.93 \\
\hline Iron Clay & 6.2 & 26.0 & 15.2 & 1.20 \\
\hline CB27 & 6.2 & 21.0 & 15.2 & 1.18 \\
\hline IT93K-503-1 & 6.2 & 28.7 & 15.2 & 1.71 \\
\hline CB5 & 6.2 & 28.2 & 15.2 & 1.54 \\
\hline UCR 671 & 6.2 & 29.4 & 15.2 & 1.27 \\
\hline 8517 & 6.2 & 23.8 & 15.2 & 1.13 \\
\hline 7964 & 6.2 & 19.3 & 15.2 & 1.15 \\
\hline IT89KD-288 & 6.2 & 37.6 & 15.2 & 2.02 \\
\hline CB46 & 6.2 & 24.4 & 15.2 & 1.48 \\
\hline
\end{tabular}

in each parameter examined, shoot dry weight, leaf area, leaf dry weight, stem dry weight, and root dry weight. The salt-tolerance model accounted for $>96 \%$ of the total salt effect among all the parameters investigated.

From our data it appears that 'UCR 134' is the most salt tolerant cultivar. It had the highest $\mathrm{C}_{50}$ value, the salinity level resulting in a 50\% yield reduction, for both leaf area and leaf dry weight. The $\mathrm{C}_{50}$ values among cultivars for stem dry weight and root dry weight did not vary. In addition 'UCR 134' was among the highest 
yielding cultivars with a total dry weight (leaf + stem + root) of $53.8 \mathrm{~g}$ dry weight per plant. However, it does not seem that high yield is an indicator of salinity stress as 'IT89KD-288', the highest yielding cultivar in our study, was very sensitive to salt with respect to both leaf area and leafdry weight. Our second highest yielding cultivar, 'UCR 671', was not particularly salt tolerant, either. The popular Coachella Valley cultivar, 'Iron Clay', was not only relatively low yielding in our greenhouse (44.6 g dry weight per plant, ninth out of 12), but was salt sensitive with respect to leaf area, although relatively tolerant in terms of leaf dry weight.

One particularly interesting observation involved the effect of salt stress on biomass yield of 'IT89KD-288'. With respect to all growth parameters examined, 'IT89KD-288' was the highest yielding under control conditions. However, based on the sharp decline of leaf area and dry weight with increasing salinity, it was the most sensitive (leaf area) or secondmost sensitive(dry weight). Surprisingly though, this sensitivity did not extend to stem dry weight or root dry weight. In these cases, 'IT89KD-288' did not differ from the other 11 cultivars. In this respect, it is interesting to note the remarkable constancy of the salt tolerance among the 12 cultivars with respect to stem dry weight and root dry weight. Whatever the nature of signals emanating from the roots or leaves that modulates growth, it appears that while the leaves of 'IT89KD-288' are more reactive to these signals than other cultivars, the stems and roots are not. Thus, 'IT89KD-288' may be a useful cultivar to investigate the signal transduction between root and shoot modulating growth under saline conditions.

A well-documented observation that upon salinity stress is the increase in the root-shoot ratio of many plants when exposed to salinity (Munns and Termaat, 1986). Our findings with cowpea (data not shown) are consistent with this observation. Unlike the shoot parameters, leaf area, leafdry weight, and stem dry weight, which sharply declined with increasing salinity, root dry weight responded more slowly to increasing salinity. This was found for all cultivars tested. Apparently, the differences in the salt response among the cultivars is a property of the leaves only and not of the other growth parameters of shoots, stems and roots. It has been postulated that changes in sugar concentrations in the roots that may influence growth (Lambers and Atkin, 1995). One interesting area of investigation would be the significance of our finding in terms of carbohydrate partitioning and alterations of root carbohydrate metabolism.

An interesting outcome to this investigation is the close agreement between our results with 'CB5' and those of Maas and Poss (1989). These authors reported a $52 \%$ decrease in shoot dry weight at $-0.35 \mathrm{MPa}$ (see Mass and Poss, 1989, Table 1). In our investigation, we calculated a $\mathrm{C}_{50}$ value for leaf dry weight for CB5 of $8.4 \mathrm{dS} \cdot \mathrm{m}^{-1}$, about $-0.31 \mathrm{MPa}$ (Table 5). It is thought that many crops are more tolerant of sulfate salinity than chloride salinity (Curtin et al., 1993; Grattan and Grieve, 1999). However, our Colorado River water based solutions were composed using $\mathrm{NaCl}, \mathrm{CaCl}_{2}$, and $\mathrm{MgSO}_{4}$ salts while Maas and Poss (1989) used only $\mathrm{NaCl}$ and $\mathrm{CaCl}_{2}$ at a 2:1 molar ratio. In contrast to many crops it would appear cowpea responds to the total salt concentration or osmotic potential without regard to the salt species present. However, such a conclusion may not be justified based solely on one observation. Since cowpea is grown in the southern San Joaquin Valley of California (Hall and Frate, 1996), a more definitive growth response study comparing high-sulfate solutions, typical of drainage waters in the San Joaquin Valley (Deveral, etal., 1984), with high-chloride waters would be useful in determining if cowpea may be used in a drainage water reuse program in the San Joaquin Valley (Rhoades and Dinar, 1991).

However, we should point out that both our results and those of Mass and Poss (1989) stand in contrast to other reported data. Our data indicate that the decrease in vegetative growth of 'CB5' by salinity in the greenhouse was greater than that reported by West and Francois (1982) in the field. They found that vegetative growth decreased by $50 \%$ at an electrical conductivity of the saturated extract ECe of about $7 \mathrm{dS} \cdot \mathrm{m}^{-1}$. Our finding of $8.4 \mathrm{dS} \cdot \mathrm{m}^{-1}$ for leaf dry weight was based on the electrical conductivity of the of the irrigation solution, ECi. Using a leaching fraction of $15 \%$ to $20 \%$, typical for most tiledrained soils, $7 \mathrm{dS} \cdot \mathrm{m}^{-1}$ ECe value would equate to about $10.5 \mathrm{dS} \cdot \mathrm{m}^{-1} \mathrm{ECi}$. This discrepancy may be explained by the fact that their study was initiated when their plants were older and the salt applied more slowly.

It should be made clear that plants in sand cultures in the greenhouse are not exposed to same conditions as in the field. Field conditions can involve more complex ionic, osmotic, and nutritional factors than in sand culture. In addition field grown plants may experience more drastic wet and dry cycles than changes in salt concentrations and temperature ranges. Additionally, we should note that we harvested our plants in early September, $53 \mathrm{~d}$ after planting when the cultivars with a normal flowering period passed flower initiation stage. The photosensitive varieties do not flower until the day length is much shorter. Thus, any advantage construed by the extra vegetative growth would not be apparent in this study. Despite these caveats, we feel our studies do demonstrate that significant differences in salt tolerance exists among cowpea cultivars in some growth parameters. The relative differences in their salt tolerance depends on which growth parameter is measured. Future research should be directed towards elucidating the physiological, biochemical, and molecular basis involved in regulating growth and carbon reallocation during salinity stress.

\section{Literature Cited}

Abdul-Baki, A., S. Aslan, E.H. Beardsley, S. Cobb, and M. Shannon. 1998. Soil water and nutritional management of date orchards in Coachella Valley and Bard. Coachella Valley Resour. Conserv. Dist., Indio, Calif.

Bower, C.A., J.R. Spencer, and L.O. Weeks. 1969. Salt and water balance, Coachella Valley, California. J. Irr. Drainage Div. ASCE Proc. Paper 6437:55-64. Curtin, D., H. Steppuhn, and F. Selles. 1993. Plant responses to sulfate and chloride salinity: Growth and ionic relations. Soil Sci. Soc. Amer. J. 57:1304-1310.

Deveral, S.J., R.J. Gilliorn, R. Fujii, J.A. Izbicki, and J.C Fields. 1984. Areal distribution of selenium and other organic constituents in shallow ground water of the San Luis Drain Service Area, San Joaquin Valley, California: A preliminary study. U.S. Geol. Survey, Sacramento, Calif., Water Resour. Investigations Rpt. 84-4319.

Ehlers, J.D. and A.E. Hall. 1997. Cowpea(Vigna unguiculata L. Walp.). Field Crops Res. 63:187-204.

Francois, L.E. 1996. Salinity effects on four sunflower hybrids. Agron. J. 88:215-219.

Francois, L.E. 1988. Salinity effects on three turf bermudagrasses. HortScience 23:706-708.

Francois, L.E., T.J. Donovan, E.V. Maas, and G.L. Rubenthaler. 1988. Effect of salinity on grain yield and quality, vegetative growth, and germination of triticale. Agron. J. 80:642-647.

Grattan, S.R. and C.M. Grieve. 1999. Salinity-mineral nutrient relations in horticultural crops. Scientia Hort. 78:127-157.

Guldan, S.J., C.A.Martin, W.C. Lindemann, J. CuetoWong, and R.L. Steiner. 1997. Yield and greenmanure benefits of interseeded legumes in a high desert environment. Agron. J. 89:757-762.

Hall, A.E. and P.N. Patel. 1985. Bredding for resistance to drought and heat, p. 137-157. In: S.R. Singh and K.O. Rachie (eds.). Cowpea research, production and utilization. Wiley, New York.

Hall, A.E. and C.A. Frate. 1996. Blackeye bean production in California. Univ. Calif. Div. Agr. Nat Res. Publ. 21518.

Hargrove, H.L. and W. Fry. 1987. The need for legume cover crops in conservation tillage production, $\mathrm{p}$. 1-4. In: J.F. Powers (ed.). The role of legumes in conservatioin tillage systems. Soil and Water Conserv. Soc., Athens, Ga.

Hutchinson, C.H. and M.E. McGiffen. 2000. Cowpea cover crop mulch for weed control in desert pepper production. HortScience 35:196-198.

Lambers, H. and O.K.Atkin. 1995. Regulation of carbon metabolism in roots, p. 226-238. In: M.A. Madore and W.J. Lucas (eds.). Carbon and partitioning and source-sink interactions in plants. Amer. Soc. Plant Physiol., Rockville, Md.

Maas, E.V.and J.A.Poss. 1989. Saltsensitivity of cowpea at various growth stages. Irr. Sci. 10:313-320.

Mayberry, K.M., E.N. Natwick, R.A. Gonzales, G.H. Holmes, C.E. Bell, and K.M. Bali 1995. Guidelines to production costs and practices, 1994-1995. Univ. Calif. Coop. Ext. Imperial Co., Holtville, Circ. 104V.

Munns, R. and A. Termaat. 1986. Whole-plantresponses to salinity. Austral. J. Plant Physiol. 13:143-160.

Powers, J.F. and P.T. Koerner. 1987. Cover crop production for several planting and harvest dates in eastern Nebraska. Agron. J. 86:1092-1097.

Rhoades, J.D. and A. Dinar. 1991. Reuse of agricultural drainage water to maximize the beneficial use of multiple water supplies for irrigation, p. 99-115. In: A. Dinar and D. Zilberman (eds.). The economics and management of water and drainage in agriculture, Kluwer Acad. Press, Boston, Mass.

SAS Institute. 1994. SAS/SAT user's guide. ver. 6. 4th ed. SAS Inst., Cary, N.C.

Van Genuchten, M.Th and G.I. Hoffman. 1984. Management aspect of crop production: 8.1. Analysis of crop salt tolerance data, p. 258-271. In: I. Shainberg and J. Shalhevet(eds.). Soil salinity under irrigation, processes and management. Ecological studies 51. Springer Verlag, New York.

West, D.W. and L.E. Francois. 1982. Effects of salinity on germination, growth and yield of cowpea. Irr. Sci. 3:169-175.

Zeng, L., M.C. Shannon, and C.M. Grieve. 2002. Evaluation of salt tolerance in rice genotypes by multiple agronomic parameters. Euphytica 127:235-245.. 